\title{
GRUPOS FLORÍSTICOS E ESPÉCIES DISCRIMINANTES EM POVOAMENTO DE Araucaria angustifolia E UMA FLORESTA OMBRÓFILA MISTA ${ }^{1}$
}

\author{
Rafael Rode ${ }^{2}$, Afonso Figueiredo Filho ${ }^{3}$, Sebastião do Amaral Machado ${ }^{4}$ e Franklin Galvão ${ }^{5}$ \\ RESUMO - Este estudo teve como objetivos a determinação de grupos florísticos, a discriminação e avaliação \\ de espécies importantes na composição florística em duas áreas de pesquisa localizadas na Floresta Nacional \\ de Irati, Estado do Paraná. Uma área com 10 ha foi instalada em um povoamento de Araucária implantado \\ há 60 anos (área A), onde espécies arbóreas se estabeleceram, enquanto que outra de 25 ha foi instalada em \\ uma Floresta Ombrófila Mista (área B). As áreas constituem-se de blocos contínuos de 1 ha (100 m x 100 m) \\ divididos em parcelas de 0,25 ha (50 m x $50 \mathrm{~m}$ ), onde todas as árvores com diâmetro a altura do peito (DAP) \\ igual ou superior a $10 \mathrm{~cm}$ foram medidas e identificadas. Foram utilizadas técnicas estatísticas multivariada, \\ análises de agrupamento e discriminante, com a finalidade de identificar a formação de grupos florísticos nas \\ áreas e as espécies discriminantes dos grupos. Uma matriz de dados foi estruturada contendo o valor de cobertura \\ da i-ésima parcela obtido da $j$-ésima espécie. Seis grupos foram identificados pela análise de agrupamento. \\ O primeiro e o segundo grupo reuniram 15 e 24 parcelas, respectivamente, e pertencentes à área A. Nos 25 ha \\ da área B foram obtidos mais 4 grupos (3, 4, 5 e 6), reunindo 28, 21, 36 e 16 parcelas. Com a análise discriminante, \\ obteve-se 12 variáveis (espécies) com poder de diferenciar os grupos formados. Realizando as análises fitossociológicas \\ dos grupos, as seguintes associações foram identificadas: associação com o povoamento de Araucaria angustifolia \\ I; associação com povoamento de Araucaria angustifolia II; associação Nectandra grandiflora; associação \\ Ocotea porosa; associação Ocotea odorifera; associação Matayba elaeagnoides.
}

Palavras-chave: Análise multivariada, Composição florística e Fitossociologia

\section{FLORISTIC GROUPS AND DISCRIMINANT SPECIES IN STANDS WITH Araucaria angustifolia AND A MIXED OMBROPHYLOUS FOREST}

\begin{abstract}
This study aimed to determine the floristic groups, the discrimination and the evaluation of important species in the floristic composition in two research areas located on the National Forest of Irati, Paraná State, Brazil. An area of 10 ha was installed in a Araucaria stand deployed 60 years ago (area A), where arboreal species were established, while another 25 ha area was installed in a Mixed Ombrophylous Forest (area B). The areas were set up from continuous blocks of $1 \mathrm{ha}(100 \mathrm{mx} 100 \mathrm{~m})$ divided into plots of $0.25 \mathrm{ha}(50 \mathrm{mx}$ $50 \mathrm{~m}$ ), where all trees with diameter at breast height (dbh) equal or higher than $10 \mathrm{~cm}$ were measured and identified. We used statistical multivariate techniques, cluster, and discriminant analysis, in order to identify the floristic groups formation in these areas and the species of discriminant groups. An array containing the data was structured containing the coverage value of the $\mathbf{i}$-th plot obtained from the $\boldsymbol{j}$-th species. Six groups were identified by cluster analysis. The first and the second group gathered 15 and 24 parcels, respectively, belonging to the area A. In the 25 ha from the area B, four groups (3, 4, 5, and 6) were obtained, gathering 28, 21, 36, and 16 plots. With discriminant analysis, we obtained 12 variables (species) that could differentiate the formed groups. Carrying out the groups' phytosociological analysis, the following associations were identified: "association with Araucaria angustifolia stand I; association with Araucaria angustifolia stand II; Nectandra grandiflora association; Ocotea porosa association; Ocotea odorifera association; Matayba elaeagnoides association.
\end{abstract}

Keywords: Multivariate analysis, Floristic composition and Phytosociology.

\footnotetext{
${ }^{1}$ Recebido em 08.11.2008 e aceito para publicação em 16.12.2010.

${ }^{2}$ Universidade Federal de Viçosa, UFV, Brasil. E-mail: <rafaelrode@gmail.com>

${ }^{3}$ Universidade Estadual do Centro-Oeste, UNICENTRO, Brasil. E-mail: <afonso@irati.unicentro.br>.

${ }^{4}$ Universidade Federal do Paraná, UFPR, Brasil. E-mail: <samachado@ufpr.br>.

${ }^{5}$ Universidade Federal do Paraná, UFPR, Brasil. E-mail: <fgalvao@ufpr.br>.
} 


\section{INTRODUÇÃO}

Na Região Sul, encontra-se uma das mais importantes formações florestais do Brasil, denominada Floresta Ombrófila Mista. Tal denominação foi inicialmente utilizada por Veloso e Góes Filho (1982) e adotada pelo IBGE (1992) na classificação fisionomicoecológica da vegetação brasileira. A concepção de Floresta Ombrófila Mista procede da ocorrência da mistura de floras de diferentes origens, definindo padrões fitofisionômicos típicos, em zonas climáticas caracteristicamente pluviais. Essa tipologia vegetal também é conhecida como Floresta com Araucária ou Mata de Araucária e, antes de ser adequadamente conhecida, foi drasticamente reduzida a inexpressivos $10 \%$ de sua superfície original, em fragmentos alterados ou descaracterizados (LEITE e KLEIN, 1990).

Atualmente, as florestas com araucária encontramse drasticamente reduzidas entre 1 e $2 \%$ de sua área original devido à intensa exploração no primeiro ciclo econômico ocorrido no Sul do Brasil. Os remanescentes dessa tipologia florestal encontram-se espalhados em fragmentos pelos Estados, protegidos por lei por possuírem extrema importância ambiental e científica. Um fragmento importante com 1.272,90 hectares (DISPERATI, 1986) é encontrado na região CentroSul do Estado do Paraná, na Floresta Nacional de Irati, ou FLONA de Irati, onde foi realizado este estudo.

A análise multivariada de dados, sendo um conjunto de ferramentas de redução, classificação ou simplesmente utilizada como técnica exploratória, torna-se útil nos estudos da ecologia, pois inúmeras são as variáveis que afetam o estabelecimento, crescimento e permanência de espécies arbóreas em diferentes ambientes. Nesse aspecto, vários pesquisadores têm estudado a ecologia das espécies em diferentes regiões fitogeográficas por meio de técnicas multivariadas, aliados aos estudos florísticos e fitossiciológicos, entre os quais podem ser citados os de: Longhi (1997), Santos et al. (2004), Souza e Souza (2006), Azevedo (2006) e Rivera (2007).

Diante da importância que representa essa tipologia florestal para o país, neste trabalho buscou-se identificar as associações florísticas que ocorrem na Floresta Ombrófila Mista e se tais associações também são de ocorrência em ambientes alterados, ou sob intensa cobertura, e, ainda, identificar quais espécies estavam dominando o ambiente e quais apresentavam dificuldades de estabelecimento.
Dessa forma, o objetivo desta pesquisa foi identificar a formação de grupos florísticos de um fragmento da Floresta Ombrófila Mista e, ainda, da vegetação arbórea estabelecida naturalmente sob um povoamento de Araucaria angustifolia na FLONA de Irati, Estado do Paraná, bem como determinar as espécies com maior poder de diferenciar os grupos formados.

\section{MATERIAL E MÉTODOS}

Este estudo foi realizado na Floresta Nacional de Irati (FLONA de Irati), na região Centro-Sul do Estado do Paraná, distante 150 km de Curitiba. O clima da região, baseando-se na classificação de Köppen, é do tipo $\mathrm{C} f b$ - Subtropical Úmido Mesotérmico, caracterizado por verões frescos, geadas severas e frequentes e sem estação seca. A FLONA está a uma altitude média de 885 m s.n.m., e a vegetação é caracterizada pela Floresta Ombrófila Mista Montana.

Os dados utilizados na pesquisa foram oriundos de duas áreas de pesquisa (A e B), constituídas por blocos contínuos de 1 ha (100 m x $100 \mathrm{~m})$, instalados com teodolito. A área A com 10 ha e a área B com 25 ha diferiam entre si principalmente por se constituírem, respectivamente, de um povoamento de Araucaria angustifolia implantado há 60 anos e um remanescente de Floresta Ombrófila Mista.

Cada bloco foi ainda dividido em parcelas com 0,25 ha (50 m x 50 m) e, para facilitar a numeração e mapeamento dos indivíduos que o compunham, cinco faixas de controle ou subparcelas de 0,05 ha (10 m x $50 \mathrm{~m}$ ) foram delimitadas em cada parcela. Todas as árvores com diâmetros à altura do peito (DAP) maiores que $10 \mathrm{~cm}$ foram medidas com fita métrica comum ou trena. A identificação botânica seguiu o Sistema de Classificação APG II (Angiosperm Phylogeny Group II) (SOUZA e LORENZI, 2005).

Para atender aos objetivos deste trabalho, os dados foram analisados em três etapas: análise de agrupamento, análise discriminante e análise da fitossociologia dos grupos florísticos identificados pelas duas técnicas multivariadas anteriores.

Para a análise de agrupamento foi utilizado o valor de cobertura de todas as espécies identificadas, independentemente da área de estudo, com o objetivo de agrupar parcelas com valores semelhantes. É importante ressaltar que esse valor de cobertura foi obtido mediante análise fitossociológica previamente 
realizada, porém não detalhada neste estudo. Assim, uma matriz (140 x 131) contendo valores de cobertura foi estruturada com a i-ésima parcela $(0,25 \mathrm{ha})$ e j-ésima espécie. Essa matriz envolveu todas as espécies e, ainda, os indivíduos não identificados. Entre as técnicas hierárquicas aglomerativas, foi utilizado o método de Ward na análise de agrupamento e para medir a proximidade entre as parcelas, a distância euclidiana quadrada (BATISTA, 1990; LONGHI, 1997; SOUZA et al., 2003; SOUZA e SOUZA, 2004; SANTOS et al., 2004).

Após a formação dos grupos florísticos pela análise de agrupamento, empregou-se a análise discriminante para determinar quais variáveis (espécies) explicam o máximo de diferenças entre os grupos, bem como estabelecer o número e composição das dimensões de discriminação entre os grupos formados por essas variáveis.

Para a seleção das variáveis, na análise discriminante foram utilizadas, primeiramente, todas as espécies (matriz primária 140 x 131) como variáveis independentes. Após avaliar os resultados da primeira análise realizada, observou-se que algumas espécies, não importantes em termos ecológicos, foram selecionadas pelo método Stepwise/backward como espécies fundamentais na diferenciação dos grupos.

Verificou-se, portanto, a necessidade de retirar algumas espécies, como as de ocorrência rara e menos importantes na caracterização de ambientes. A remoção das espécies foi feita de forma empírica, e iniciou-se observando os seguintes critérios: 1) espécies não identificadas; 2) frequência em até duas parcelas; e 3) frequência em três até cinco parcelas, desde que não estivessem agrupadas.

A avaliação geral dos modelos (função discriminante) foi feita com matrizes de classificação, utilizando-se os métodos da resubstituição e validação cruzada ou Lachenbruch (JOHNSON e WICHERN, 2002; MINGOT, 2003).

Após a aplicação das técnicas multivariadas, realizou-se a análise fitossociológica dos grupos formados no povoamento e na floresta, para identificar as associações florísticas e as espécies com maior ou menor potencial de desenvolvimento nesses dois ambientes. Os grupos foram comparados quanto ao valor de importância relativo, bem como as variáveis que o compõem, a densidade, a dominância e a frequência.
Para realizar as análises multivariadas, foi utilizado o sistema SPSS e para as análises fitossociológicas, o Microsoft Office Excel.

\section{RESULTADOS E DISCUSSÃO}

Os resultados da análise de agrupamento utilizando a matriz primária encontram-se na Figura 1. Na floresta (área B) foram formados quatro grupos, enquanto no povoamento (área A), dois. É importante ressaltar que apenas uma parcela da área A foi agrupada com o grupo 3 da área B, provavelmente por apresentar menor densidade de araucárias plantadas em relação às demais parcelas da área $\mathrm{A}$, o que favorece o desenvolvimento da regeneração.

Para a análise discriminante foram retiradas as espécies menos importantes, de acordo com os critérios descritos na metodologia, reduzindo-se o valor de cobertura total de 200 para 199,3\%. Isso mostra que os critérios utilizados, embora empíricos, foram muito cautelosos e com a vantagem de uma pré-remoção de 40 variáveis (espécies). Dessa forma, a matriz primária de 140 x 131 foi reduzida para uma matriz secundária de $140 \times 91$.

Para seleção das variáveis independentes, autores como Hair et al. (1998) e Mingoti (2005) comentaram o critério de significância-padrão de 0,05 e para o método Stepwise, o uso de 0,1,; 0,2; e, ainda, 0,5.

Esses altos valores são aplicáveis, quando na prática não se conseguem variáveis significativas para a discriminação. Nesta pesquisa ocorreu justamente

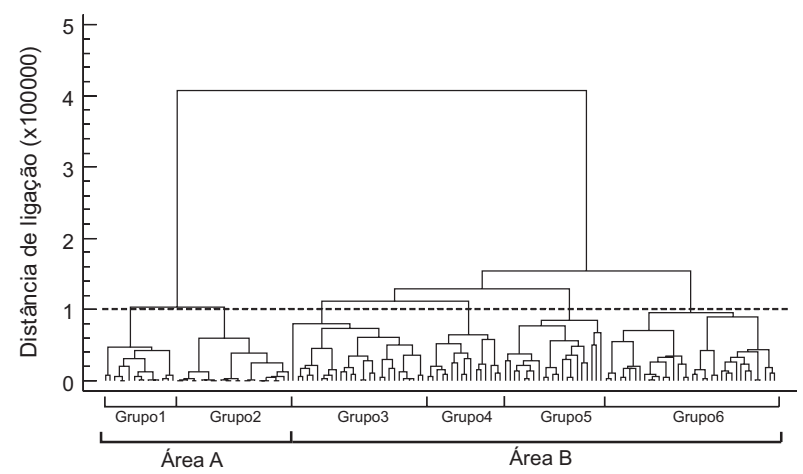

Figura 1 - Dendrograma (cluster) agrupando parcelas (0,25ha) pelo método de ligação ward e a distância euclidiana quadrada.

Figure 1 - Dendrogram (cluster) grouping plots (0.25ha) with the Ward method and the square Euclidian distance.

Revista Árvore, Viçosa-MG, v.35, n.2, p.319-327, 2011 
o oposto. Com nível de significância de 0,05, muitas variáveis independentes foram selecionadas (37), indicando que a escolha de $\mathrm{F}$ deve-se ater particularmente a cada objetivo, dependendo, ainda, da magnitude dos dados.

De acordo com Murray (1977), deve-se escolher subconjunto de variáveis que forneçam o menor número de classificações erradas na base de dados. Para mais de 14 ou 15 variáveis, o número de subconjuntos envolvidos dificulta o tratamento, e deve-se considerar alguma forma de procedimento sequencial. Assim, após observar que nesse processo não houve perda na classificação cruzada ao diminuir a probabilidade de F de 0,05 para 0,001, optou-se pela utilização deste último, por reduzir o número de variáveis de 37 para 12 .

Na Tabela 1, observam-se as 12 variáveis (espécies) que foram selecionadas após 12 passos (steps). A estatística lâmbda $\left(\lambda^{*}\right)$ indica que, em nível de $0,1 \%$ de significância (99,9\% de probabilidade), essas variáveis possuem alto poder discriminante.

Cinco funções discriminantes foram selecionadas para explicar a variável dependente (grupos). A primeira função representou $81,2 \%$ da variância explicada pelas cinco funções. O resultado elevado do autovalor $(29,92)$ confirma a predominância dessa função sobre as demais, que apresentaram autovalores menores que 3 , e, ainda, sua correlação foi a mais alta $(0,98)$, sendo a quinta função que teve a menor correlação $(0,5)$. As cinco funções discriminantes geradas foram necessárias para explicar $100 \%$ da variância total.
Na Tabela 2, encontram-se os coeficientes padronizados das funções discriminantes canônicas, os quais são computados de forma que seus escores estejam padronizados com média zero e variância 1 . O sinal negativo deve ser omitido na interpretação da contribuição das variáveis (LONGHI, 1997).

Na primeira função discriminante padronizada, destacou-se Araucaria angustifolia (Bertol.) Kuntze e na segunda, Ocotea odorifera (Vellozo) Rohwer. Na terceira função, Allophylus edulis (A. St.-Hil., Cambess. \& A. Juss.) Radlk e Ocotea porosa (Ness \& C. Mart.) Barroso foram as mais importantes, enquanto Cabralea canjerana (Vell.) Mart. e Citronella paniculata (Mart.) R. A. Howard se destacaram na quarta função. Finalmente, na quinta função, predominou Nectandra grandiflora Nees \& C. Mart. Ex Nees. As demais espécies da Tabela 2 possuem importância indireta, como o caso de Alchornea triplinervia (Spreng.) Müll. Arg., com relevância nas funções 4 e 5 e menor valor nas funções 1, 2 e 3 .

Avaliando a precisão de classificação das funções discriminantes, através de matrizes de classificação, foi observado que as funções atingiram grau elevado de precisão. A proporção de sucesso pelo método da resubstituição foi de $96,4 \%$, enquanto pelo método da validação cruzada, 90\%. Por esses resultados, verificouse o viés ascendente, que é típico quando se aplica somente a análise de amostra (resubstituição), mas não a uma amostra de validação (HAIR et al., 1998; MINGOTI, 2005).

Na Tabela 3 consta o número de parcelas que cada grupo envolveu, bem como o número de indivíduos, o número de espécies, a área basal e, ainda, as principais espécies discriminantes. Observa-se, nessa tabela, que os grupos 1 e 6 foram os que apresentaram menor

Tabela 1 - Estatística do teste de seleção de variáveis discriminantes, em ordem de entrada após 12 steps. Table 1 - Statistics of the selection test from discriminant variables in entrance order, after 12 steps.

\begin{tabular}{|c|c|c|c|c|}
\hline$\overline{\text { Steps }}$ & Variável & Lambda de Wilks $\left(\lambda^{*}\right)$ & $F$ & Significância( $p$-nível) \\
\hline 1 & Araucaria angustifolia & 0,00433 & 67,7887 & 0,0000 \\
\hline 2 & Ocotea odorifera & 0,00243 & 28,9073 & 0,0000 \\
\hline 3 & Ocotea porosa & 0,00143 & 7,2907 & 0,0000 \\
\hline 4 & Cabralea canjerana & 0,00196 & 18,9152 & 0,0000 \\
\hline 5 & Pitptocarpha tomentosa & 0,00143 & 7,4529 & 0,0000 \\
\hline 6 & Psidium cattleyanum & 0,00146 & 8,1281 & 0,0000 \\
\hline 7 & Citronella paniculata & 0,00149 & 8,7882 & 0,0000 \\
\hline 8 & Alchornea triplinervia & 0,00135 & 5,6390 & 0,0001 \\
\hline 9 & Cupania vernalis & 0,00132 & 4,9795 & 0,0003 \\
\hline 10 & Matayba elaeagnoides & 0,00139 & 6,4729 & 0,0000 \\
\hline 11 & Allophylus edulis & 0,00134 & 5,3673 & 0,0002 \\
\hline 12 & Nectandra grandiflora & 0,00132 & 4,8752 & 0,0004 \\
\hline
\end{tabular}

Revista Árvore, Viçosa-MG, v.35, n.2, p.319-327, 2011 
Tabela 2 - Coeficientes padronizados das funções discriminantes canônicas.

Table 2 - Standardized coefficients of canonical discriminant functions.

\begin{tabular}{lcccc}
\hline Variáveis & Função 1 & Função 2 & Função 3 & Função 4 \\
\hline Alchornea triplinervia & 0,16070 & 0,06027 & 0,00690 & $-0,46473$ \\
Allophylus edulis & 0,02875 & $-0,15677$ & 0,49888 & 0,02092 \\
Araucaria angustifolia & 0,92940 & 0,08407 & 0,06727 & $-0,31099$ \\
Cabralea canjerana & 0,47275 & 0,01606 & $-0,03557$ & 0,90015 \\
Citronella paniculata & 0,28469 & $-0,02292$ & 0,00357 & 0,16072 \\
Cupania vernalis & $-0,14613$ & $-0,09089$ & 0,44624 & $-0,13662$ \\
Matayba elaeagnoides & 0,06194 & 0,03912 & 0,51916 & 0,03654 \\
Nectandra grandiflora & 0,04911 & $-0,17795$ & 0,12415 & 0,14523 \\
Ocotea odorifera & $-0,16517$ & 0,88751 & $-0,03306$ & $-0,21475$ \\
Ocotea porosa & $-0,18404$ & $-0,21114$ & $-0,54272$ & $-0,06027$ \\
Piptocarpha tomentosa & 0,44387 & 0,12003 & $-0,01759$ & 0,00845 \\
Psidium cattleyanum & 0,41140 & 0,04029 & $-0,05263$ & 0,31792 \\
\hline
\end{tabular}

Tabela 3 - Agrupamento das parcelas e as principais espécies discriminantes em cada grupo.

Table 3 - Plots grouping and the main discriminant species in each group.

\begin{tabular}{|c|c|c|c|c|c|c|}
\hline$\overline{\text { Grupo }}$ & Espécies mais discriminantes & $\begin{array}{c}\text { Número de } \\
\text { parcelas }\end{array}$ & Área (ha) & $\mathrm{N}^{\circ}$ (Ind.) & $\mathrm{N}\left(\mathrm{ha}^{-1}\right)$ & $\begin{array}{c}\text { Área } \\
\text { basal }\left(\mathrm{m}^{2} \cdot \mathrm{ha}^{-1}\right)\end{array}$ \\
\hline 1 & $\begin{array}{l}\text { Cabralea canjerana } \\
\text { Citronella paniculata }\end{array}$ & 15 & 3,75 & 2810 & 749 & 36,15 \\
\hline 2 & Alchornea triplinervia & 24 & 6,00 & 4753 & 792 & 40,75 \\
\hline 3 & Nectandra grandiflora & 28 & 7,00 & 3967 & 567 & 34,11 \\
\hline 4 & Ocotea porosa & 21 & 5,25 & 2300 & 438 & 24,77 \\
\hline 5 & Ocotea odorifera & 36 & 9,00 & 5426 & 603 & 29,07 \\
\hline 6 & $\begin{array}{l}\text { Allophylus edulis } \\
\text { Matayba elaeagnoides } \\
\text { Cupania vernalis }\end{array}$ & 16 & 4,00 & 2317 & 579 & 31,21 \\
\hline
\end{tabular}

agrupamento de parcelas (15 e 16), tendo, portanto, menor área (3,75 e 4 ha), porém o grupo 1, apesar de ter menor área que o grupo 6, teve maior número de indivíduos. Essa diferença também foi observada entre os grupos da área A (1 e 2) e da área B (3 a 6), devido ao plantio de Araucaria angustifolia. O grupo 5 foi o que apresentou maior agrupamento de parcelas (36), sendo Ocotea odorifera a espécie em destaque, com maior capacidade de diferenciar esse grupo dos demais.

A fitossociologia permitiu entender melhor a importância das espécies que ocorrem em cada grupo florístico. Os resultados são apresentados na Tabela 4, com as sete primeiras espécies em valor de importância (VI\%) por grupo. De acordo com as características de cada grupo e espécies que ocorrem, foram nomeadas as seguintes associações florísticas:

\section{Associação com povoamento de Araucaria angustifolia I (grupo 1)}

Araucaria angustifolia é a espécie com maior valor de importância (VI = 107,3\%) esperado para um grupo do povoamento. A área basal foi de $26,16 \mathrm{~m}^{2}$.ha-1 para
235 indivíduos.ha ${ }^{-1}$. Em termos relativos, a dominância (72\%) é maior que a densidade (31\%), indicando que a estrutura horizontal das araucárias plantadas é totalmente diferente da regeneração de outras espécies, com maior porcentagem de densidade, em relação à dominância. Myrsine umbellata Mart., Cabralea canjerana, Casearia sylvestris Sw. e Psychotria vellosiana Berg. são as quatro espécies mais importantes da regeneração, com valor de importância acima de 10\%.

\section{Associação com povoamento de Araucaria angustifolia II (grupo 2)}

Neste grupo, as araucárias possuem maior densidade (377 indivíduos.ha-1) e maior área basal (34,09 m².ha-1) que as do grupo 1 . Observa-se que o valor de importância das araucárias foi de $136,4 \%$, sendo $29,1 \%$ a mais que o do grupo 1 .

Entre as espécies estabelecidas, apresentam-se também para esse grupo quatro espécies do grupo 1, com diferença na ordem de importância. Psychotria vellosiana, que foi a quarta mais importante do grupo 1 $(\mathrm{VI}=10,6 \%)$, passa a dominar o grupo $2(\mathrm{VI}=16,5 \%)$,

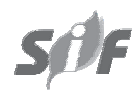

Revista Árvore, Viçosa-MG, v.35, n.2, p.319-327, 2011 
juntamente com Myrsine umbellata (VI = 15,6\%). Casearia sylvestris manteve-se praticamente com o valor de importância, variando entre 11 e $12 \%$ nos grupos 1 e 2, respectivamente, enquanto Cabralea canjerana, a terceira do grupo 1, baixou para a quinta espécie nesse grupo (VI = 11,3\%).
Destacou-se nesse grupo Alchornea triplinervia com $12,1 \%$ de VI, sendo a terceira mais importante da regeneração. Em comparação com o grupo 1, o VI foi de $5,7 \%$. O sucesso dessa espécie nesse grupo se deveu à maior densidade e dominância das araucárias e por ser considerada espécie pioneira e, ainda, facultativa.

Tabela 4 - Parâmetros fitossociológicos dos seis grupos florísticos para as sete espécies com maior valor de importância ( $\mathrm{N}$ = número de indivíduos; $\mathrm{DA}$ = densidade absoluta; $\mathrm{DR}$ = densidade relativa; DoA = dominância absoluta; DoR = dominância relativa; FA = frequência absoluta; VI = valor de importância; VC = valor de cobertura).

Table 4 - Phytosociological parameters of the six floristic groups from the seven species with the highest importance value ( $N$ = number of individuals; $A D=$ absolute density; $R D=$ relative density; $A D o=$ absolute dominance; $R D o=$ relative dominance; $A F=$ absolute frequency; $I V=$ importance value $;$ and $C V=$ covering value).

\begin{tabular}{|c|c|c|c|c|c|c|c|}
\hline Grupo & Espécies & $\mathrm{N}$ (Ind.) & DA (Ind.ha ${ }^{-1}$ ) & $\operatorname{DoA}\left(\mathrm{m}^{2} \mathrm{ha}^{-1}\right)$ & FA\% & $\mathrm{V} \mathrm{C} \%$ & V I\% \\
\hline \multirow{7}{*}{1} & Araucaria angustifolia & 883 & 235,47 & 26,16 & 100,00 & 103,78 & 107,33 \\
\hline & Myrsine umbellata & 297 & 79,20 & 1,06 & 100,00 & 13,50 & 17,06 \\
\hline & Cabralea canjerana & 210 & 56,00 & 0,90 & 100,00 & 9,95 & 13,50 \\
\hline & Casearia sylvestris & 167 & 44,53 & 0,55 & 100,00 & 7,46 & 11,01 \\
\hline & Psychotria vellosiana & 148 & 39,47 & 0,65 & 100,00 & 7,08 & 10,63 \\
\hline & Cedrela fissilis & 93 & 24,80 & 0,70 & 100,00 & 5,23 & 8,79 \\
\hline & Piptocarpha tomentosa & 68 & 18,13 & 0,36 & 93,33 & 3,43 & 6,74 \\
\hline \multirow{7}{*}{2} & Araucaria angustifolia & 2264 & 377,33 & 34,09 & 100,00 & 131,28 & 136,43 \\
\hline & Psychotria vellosiana & 424 & 70,67 & 1,17 & 91,67 & 11,79 & 16,51 \\
\hline & Myrsine umbellata & 402 & 67,00 & 0,79 & 100,00 & 10,41 & 15,56 \\
\hline & Alchornea triplinervia & 244 & 40,67 & 0,90 & 91,67 & 7,35 & 12,07 \\
\hline & Casearia sylvestris & 285 & 47,50 & 0,55 & 95,83 & 7,35 & 12,29 \\
\hline & Cabralea canjerana & 226 & 37,67 & 0,55 & 100,00 & 6,11 & 11,26 \\
\hline & Cedrela fissilis & 118 & 19,67 & 0,39 & 95,83 & 3,45 & 8,38 \\
\hline \multirow{7}{*}{3} & Araucaria angustifolia & 437 & 64,74 & 12,53 & 100,00 & 47,76 & 50,66 \\
\hline & Nectandra grandiflora & 391 & 57,93 & 2,71 & 100,00 & 17,79 & 20,69 \\
\hline & Ilex paraguariensis & 410 & 60,74 & 1,59 & 100,00 & 15,00 & 17,90 \\
\hline & Ocotea porosa & 136 & 20,15 & 3,05 & 77,78 & 12,38 & 14,63 \\
\hline & Ocotea puberula & 117 & 17,33 & 1,71 & 96,30 & 7,96 & 10,76 \\
\hline & Casearia decandra & 221 & 32,74 & 0,73 & 100,00 & 7,71 & 10,61 \\
\hline & Cedrela fissilis & 98 & 14,52 & 1,27 & 100,00 & 6,20 & 9,10 \\
\hline \multirow{7}{*}{4} & Ocotea porosa & 225 & 42,86 & 5,83 & 100,00 & 33,32 & 36,71 \\
\hline & Araucaria angustifolia & 173 & 32,95 & 4,79 & 100,00 & 26,87 & 30,26 \\
\hline & Ilex paraguariensis & 339 & 64,57 & 1,90 & 100,00 & 22,41 & 25,80 \\
\hline & Casearia decandra & 115 & 21,90 & 0,55 & 95,24 & 7,21 & 10,44 \\
\hline & Nectandra grandiflora & 86 & 16,38 & 0,79 & 100,00 & 6,93 & 10,32 \\
\hline & Cedrela fissilis & 63 & 12,00 & 1,02 & 71,43 & 6,84 & 9,26 \\
\hline & Myrsine umbellata & 91 & 17,33 & 0,41 & 76,19 & 5,62 & 8,20 \\
\hline \multirow{7}{*}{5} & Ocotea odorifera & 1075 & 119,44 & 3,56 & 100,00 & 32,07 & 35,08 \\
\hline & Araucaria angustifolia & 291 & 32,33 & 6,34 & 100,00 & 27,16 & 30,17 \\
\hline & Ilex paraguariensis & 370 & 41,11 & 1,30 & 100,00 & 11,29 & 14,30 \\
\hline & Casearia decandra & 349 & 38,78 & 0,97 & 100,00 & 9,78 & 12,79 \\
\hline & Nectandra grandiflora & 226 & 25,11 & 1,57 & 94,44 & 9,58 & 12,42 \\
\hline & Cedrela fissilis & 140 & 15,56 & 1,51 & 97,22 & 7,77 & 10,69 \\
\hline & Syagrus romanzoffiana & 218 & 24,22 & 0,99 & 97,22 & 7,43 & 10,36 \\
\hline \multirow{7}{*}{6} & Araucaria angustifolia & 152 & 38,00 & 6,29 & 100,00 & 26,71 & 29,68 \\
\hline & Nectandra grandiflora & 212 & 53,00 & 2,54 & 100,00 & 17,30 & 20,27 \\
\hline & Ilex paraguariensis & 253 & 63,25 & 1,64 & 100,00 & 16,19 & 19,16 \\
\hline & Matayba elaeagnoides & 159 & 39,75 & 2,89 & 100,00 & 16,13 & 19,11 \\
\hline & Ocotea puberula & 98 & 24,50 & 3,02 & 100,00 & 13,90 & 16,87 \\
\hline & Cedrela fissilis & 73 & 18,25 & 1,83 & 100,00 & 9,03 & 12,00 \\
\hline & Casearia decandra & 153 & 38,25 & 0,72 & 93,75 & 8,90 & 11,69 \\
\hline
\end{tabular}

Revista Árvore, Viçosa-MG, v.35, n.2, p.319-327, 2011 
A prática de desbaste na área do povoamento muito provavelmente não foi a mesma em toda a área, podendo ser a razão da formação dos dois grupos na análise de agrupamento. Segundo informações da época do plantio, esse experimento se localiza entre dois talhões e com idade de 55 e 61 anos, respectivamente, na idade da coleta dos dados (2004-05).

Se essas condições favoreceram a presença de Alchornea triplinervia nesse grupo e não no grupo 1, então a análise discriminante detectou e selecionou a espécie como discriminante desse ambiente.

As espécies que ocorrem no grupo 2 são praticamente as mesmas do grupo 1 (95\%), porém em número menor, devido às suas características. Isso indica que, em processo natural, essas espécies são “forçadas” a sair do ambiente por não serem competitivas, mas outras espécies de diferentes exigências ambientais poderão se destacar.

\section{Associação Nectandra grandiflora (grupo 3)}

Este foi o segundo maior grupo do estudo, e destacaram-se Araucaria angustifolia, Nectandra grandiflora, Ilex paraguariensis A. St.-Hil., Ocotea porosa, Ocotea puberula (Rich.) Nees e Casearia decandra Jacq. como as seis mais importantes.

Araucaria angustifolia e Nectandra grandiflora (canela-amarela) estão presentes nos quatro grupos da floresta, mas neste, possuem valor de importância pouco acima, principalmente a araucária (VI = 51\%). Essa diferença foi detectada pela análise discriminante.

A parcela 3 da área A foi determinada como semelhante em valor de cobertura com 27 parcelas da área B. Analisando as araucárias plantadas nessa parcela, foram encontrados 26 indivíduos (104 indivíduos.ha ${ }^{-1}$ ), indicando densidade muito baixa, em comparação com o grupo 1 (218 indivíduos.ha-1).

Essa baixa densidade proporcionou o estabelecimento de maior número de espécies da regeneração, sendo comparável com parcelas da área B (grupo 3).

\section{Associação Ocotea porosa (grupo 4)}

Este grupo possui 82 espécies e apresentou a menor dominância de todos $\left(24,77 \mathrm{~m}^{2} \cdot \mathrm{ha}^{-1}\right)$, sendo Ocotea porosa, Araucaria angustifolia, Ilex paraguariensis, Casearia decandra e Nectandra grandiflora com maiores valores de importância, 37, 30, 26, 10 e 10\%, respectivamente.
A principal característica do grupo se dá pela presença de Ocotea porosa (imbúia), superando os valores de densidade e dominância da araucária. Klein (1960) e Maack (1968) já haviam relatado a associação de Araucaria angustifolia e Ocotea porosa, também com a presença de Ilex paraguariensis, Nectandra grandiflora e Cedrela fissilis Vell.

A imbúia, às vezes, infiltra-se nas florestas mais abertas e em capoeirões. É, possivelmente, a espécie arbórea mais longeva da floresta com araucária, podendo ultrapassar os 500 anos de idade (CARVALHO, 2003). É característica da Floresta Ombrófila Mista Montana e pode ocupar o dossel, formando, eventualmente, populações densas, os chamados imbuiais (SILVA e MARCONI, 1990).

\section{Associação canela-sassafrás (grupo 5)}

A análise de agrupamento envolveu maior número de parcelas (36) nesse grupo e, portanto, maior número de árvores (5.426). A densidade foi de 603 indivíduos.ha ${ }^{-1} \mathrm{e}$ a dominância, de $29 \mathrm{~m}^{2} \cdot \mathrm{ha}^{-1}$.

As sete espécies mais importantes foram Ocotea odorifera como a primeira, com VI de 35\%, seguida por Araucaria angustifolia com 30\%, 14\% para Ilex paraguariensis, Casearia decandra com $13 \%$, Nectandra grandiflora 12\%, Cedrela fissilis com 11\% e Syagrus romanzoffiana (Cham.) e Glassman com 10\%.

A espécie Ocotea odorifera (canela-sassafrás) ocorre no Brasil desde o Sul da Bahia até o Rio Grande do Sul. É espécie secundária tardia ou climática exigente de luz (REITZ et al., 1979; CARVALHO, 2003), ou seja, quando jovem tolera a sombra, mas quando atingem a maturidade requer maior intensidade de luz.

Na indústria química é de ampla utilização, pois dessa canela se extrai um óleo precioso denominado safrol, utilizado para vários fins, notadamente como fixador de perfume. Esse valioso produto é obtido da destilação não só do tronco, mas também da casca, folhas e raízes (SANTOS, 1987).

\section{Associação Matayba elaeagnoides (grupo 6)}

Esse é o menor grupo da área $\mathrm{B}$, destacando-se Matayba elaeagnoides Radlk. como discriminante do grupo. O VI é o quarto do grupo (19\%). As demais espécies podem ser comparadas com as do grupo 3, em que a mais importante é Araucaria angustifolia, com VI de $30 \%$, Nectandra grandiflora com $20 \%$, Ilex paraguariensis com 19\% e Ocotea puberula com $17 \%$. 
Observa-se que Cedrela fissilis (cedro) ocorreu em todos os grupos com pouca variação do valor de importância (9\%), no grupo 1 a 12\% no grupo 6, indicando sua plasticidade, incluindo locais com altas densidades, como o caso das araucárias plantadas do grupo 2 .

Assunção (2004), trabalhando com marcador molecular RAPD (DNA polimórfico amplificado ao acaso) para conhecimento da diversidade genética de Cedrela fissilis, utilizou 19 indivíduos adultos oriundos da Mata do Galego, no Município de Luminárias, no Sul de Minas Gerais, constatando alta divergência na população observada e amplitude das distâncias genéticas variando de 7 a 68\%. Concluiu que Cedrela fissilis é espécie promissora para futuros programas de conservação e melhoramento genético florestal.

Nectandra grandiflora é encontrada nos quatro grupos da área B, com VI acima de 10\%, constatando sua importância na Floresta Ombrófila Mista. Porém, em ambientes com alta cobertura de araucária, a espécie não se destacou, pelo fato de que nos grupos da área A o VI não foi maior que 1\%. Isso indica que a espécie pode estar entrando no sistema, por ser climácica, ou encontrou algum fator limitante para seu estabelecimento.

Segundo Odum (1983), a presença e sucesso de um organismo ou de um grupo de organismos dependem de um complexo de condições. Diz-se que qualquer condição que se aproxime ou exceda os limites de tolerância é condição limitante ou fator limitante.

Constatou-se ainda que Myrsine umbellata ocorre na área B com importância considerável pelo seu valor, que variou de 5\% (grupo 6) a 10\% (grupo 5). Quando o ambiente possui maior cobertura, a espécie passa a ser mais expressiva, como observado pelos valores de importância dos grupos do povoamento (VI entre 16 e 17\%).

\section{CONCLUSÕES}

A análise de agrupamento usando o valor de cobertura agrupou as 140 parcelas usadas no estudo em seis grupos florísticos.

Pelo método Stepwise na análise discriminante, foram selecionadas 12 variáveis (espécies) com poder de distinção dos seis grupos formados na análise de agrupamento.

Com a análise fitossociológica dos grupos, foi possível revelar seis associações florísticas pelo valor de importância das espécies, sendo duas na área com povoamento de araucária e quatro na Floresta Ombrófila Mista.

\section{REFERÊNCIAS}

ASSUNÇÃO, N. S. Divergência genética em Cedrela fissilis Vell. obtida por marcadores RAPD. 2004. 30f. Monografia (Graduação em Engenharia Florestal) Universidade Federal de Lavras, Lavras, 2004.

AZEVEDO, C. P. Dinâmica de florestas submetidas a manejo na Amazônia Oriental: Experimentação e simulação. 2006. 236f. Tese (Doutorado em Manejo Florestal) - Universidade Federal do Paraná, Curitiba, 2006.

BAtista, J. Análise Multivariada no planejamento de extensão florestal: subsídios para uma política de reocupação de áreas. 1990. 137f. Dissertação (Mestrado em Ciências Florestais) - Universidade Federal do Paraná, Curitiba, 1990.

CARVALHO, P. E. R. Espécies florestais brasileiras. Brasília: Embrapa Informação Tecnológica; Colombo-PR: Embrapa Florestas, 2003. 1039p.

DISPERATI, A. A. Mapeamento florestal da Floresta Nacional de Irati - PR. Curitiba: FUPEF, 1986. 18 p. + 1 mapa.

HAIR JR, J. F. et al. Análise multivariada de dados. Porto Alegre: 1998. Trad. Bookman, 2005. 593p.

INSTITUTO BRASILEIRO DE GEOGRAFIA E ESTATISTICA - IBGE. Manual técnico da vegetação brasileira. Rio de Janeiro: 1992. (Série Manuais Técnicos em Geociências, n. 1).

JOHnson, R. A.; WICHERn, D. W. Applied multivariate statistical analyis. Madison: Prentice Hall, 1982. 607p

KLEIN, R. M. Aspecto dinâmico do pinheirobrasileiro. Sellowia, v.12, n.12, p.17-48, 1960.

LEITE, P. F.; KLEIN, R. M. Vegetação. In: INSTITUTO BRASILEIRO DE GEOGRAFIA E ESTATISTICA - IBGE. Geografia do Brasil: Região Sul. Rio de Janeiro: 1990. v.2. 419p.

LONGHI, S. J. Agrupamento e análise fitossociológica de comunidades florestais na sub-bacia hidrográfica do Rio Passo Fundo-RS. 1997. 198f. Tese (Doutorado em Engenharia Florestal) Universidade Federal do Paraná, Curitiba, 1997. 
MAACK, R. Geografia física do Estado do Paraná. Rio de Janeiro: José Olympio, 1968. 450p.

Mingoti, S. A. Análise de dados através de métodos de estatística multivariada: uma abordagem aplicada. Belo Horizonte:

Universidade Federal de Minas Gerais, 2005. 297p.

MURRAY, G. D. A cautionary note on selection of variables in discriminant analysis. Applied Statistics, v.26, n.3, p.246-250, 1977.

ODUM, E. P. Ecologia. CBS College Publishing, 1983. 434p. Tradução C. J. Trib. Rio de Janeiro: Guanabara Koogan, 1988.

RIVERA, H. Ordenamento territorial de áreas florestais utilizando avaliação multicritério apoiada por geoprocessamento, fitossociologia e análise multivariada. 2007. 225f.

Dissertação (Mestrado em Manejo Florestal) Universidade Federal do Paraná, Curitiba, 2007.

REITZ, R.; KLEIN, R. M.; REIS, A. Madeiras do Brasil. Florianópolis: Lunardelli, 1979. 320p.

SANTOS, E. Nossas madeiras. Belo Horizonte: Itatiaia, 1987. 313p.

SANTOS, J. H. S. et al. Distinção de grupos ecológicos de espécies florestais por meio de técnicas multivariadas. Revista Árvore, v.28, n.3, p.387-396, 2004.
SILVA, F. C.; MARCONI, L. P. Fitossociologia de uma floresta com araucária em Colombo-PR. Boletim de Pesquisa Florestal, n.20, p.23-38, 1990.

SOUZA, D. R. et al. Emprego de análise multivariada para estratificação vertical de florestas ineqüiâneas. Revista Árvore, v.27, n.1, p.59-63, 2003.

SOUZA, D. R.; SOUZA, A. L. Estratificação vertical em Floresta Ombrófila Densa de Terra Firme, Amazônia Oriental. Revista Árvore, v.28, n.5, p.691-698, 2004.

SOUZA, A. L.; SOUZA, D. R. Análise multivariada para estratificação volumétrica de uma Floresta Ombrófila Densa de terra firme, Amazônia Central. Revista Árvore, v.30, n.1, p.49-54, 2006.

SOUZA, V. C.; LORENZI, H. Botânica sistemática: guia ilustrado para identificação das famílias de Angiospermas na flora brasileira, baseado em APG II. Nova Odessa: Instituto Plantarum, 2005. 639p.

VELOSO, H. P.; GÓES FILHO, L. Fitogeografia Brasileira: Classificação fisionômica-ecológica da vegetação neotropical. In: PROJETO RADAMBRASIL, Salvador. 1982. (Boletim Técnico. Série vegetação, 1). 
